\title{
Novel design of a microstructured reactor allowing fast temperature oscillations
}

\author{
M. Luther ${ }^{\mathrm{a}, \mathrm{b}, *}$, J.J. Brandner ${ }^{\mathrm{a}}$, K. Schubert ${ }^{\mathrm{a}}$, \\ A. Renken ${ }^{\text {}}$, L. Kiwi-Minsker ${ }^{b}$ \\ ${ }^{a}$ Forschungszentrum Karlsruhe, Institute for Microprocess Engineering, \\ D-76344 Eggenstein-Leopoldshafen, Germany \\ ${ }^{\mathrm{b}}$ École Polytechnique Fédérale de Lausanne, CH-1015 Lausanne, Switzerland
}

\begin{abstract}
Two types of stainless steel microstructured reactors for catalytic gas-phase reactions have been developed and characterized with respect to their thermal behaviour under non-stationary temperature conditions. One of the reactors used (FTC-I) allowed periodic temperature changes up to $100 \mathrm{~K}$ with a frequency of $0.05 \mathrm{~Hz}$. However, a broad temperature gradient of $80 \mathrm{~K}$ developed inside the reactor. A second reactor (FTC-II) enabled periodic temperature variations of maximum $60 \mathrm{~K}$ with a frequency of $0.06 \mathrm{~Hz}$ while avoiding temperature non-homogeneity. The CO oxidation taken as a test reaction was carried out over a Pt/ $/ \mathrm{Al}_{2} \mathrm{O}_{3}$ catalyst in the FTC-II reactor. In this way it was possible to study the effect of non-stationary temperature conditions on the reactor performance. A significant increase in $\mathrm{CO}$ conversion was observed with periodic temperature cycling as compared to values obtained under steady-state conditions.
\end{abstract}

(C) 2007 Elsevier B.V. All rights reserved.

Keywords: Microstructured reactor; Unsteady-state operation; CO oxidation; Temperature oscillations

\section{Introduction}

Commonly chemical reactors are operated under stationary conditions after optimization of their reaction parameters. Selectively imposed regular variations of reaction parameters like concentration, pressure or temperature improve the product selectivity and yield for some reactions. The values attained exceed steady-state values as shown by Silveston et al. [1]. In most of the studies on unsteady-state or periodic operation, the parameters to vary are pressure or concentration of the reactants, but not the reaction temperature. This is due to the high thermal inertia of conventional chemical reactors. In these reactors fast and reproducible temperature changes are difficult to obtain. The experimental study by Hansen and Joergensen [2] was the first report on the performance of fixed bed reactors under forced temperature variations. But the theoretically predicted increase in performance of catalytic reactor [3] has not been observed up to now.

\footnotetext{
* Corresponding author at: Forschungszentrum Karlsruhe, IMVT, Hermannvon-Helmholtz Platz 1, D-76344 Eggenstein-Leopoldshafen, Germany. Tel.: +49 7247 826657; fax: +49 7247823186.

E-mail address: martin.luther@imvt.fzk.de (M. Luther).
}

Microstructured reactors developed during the last decade have low thermal inertia and therefore allow temperature changes up to $100^{\circ} \mathrm{C}$ within few seconds [4]. This opens an opportunity to validate experimentally theoretical predictions. Brandner [4] recently reported the qualitative features of increased conversion under non-stationary temperature conditions compared to thermal steady-state reactor values. Catalytic $\mathrm{CO}$ oxidation was taken as the model reaction.

This work provides quantitative data for an increase in $\mathrm{CO}$ oxidation rate under fast periodic temperature oscillations. We report two types of microstructured reactors, which have been developed and characterized towards this objective.

\section{Experimental}

\subsection{Microstructured reactors}

The first microstructured reactor (FTC-I) used during this work has been discussed elsewhere [4,5]. It consists of three metal plates with eight holes for electric heater cartridges and three hole channels for thermocouples as presented in Fig. 1. Three cooling and two microstructured foils with reaction channels are placed symmetrically above and under the central heating plate in alternating order. The reactor parts are made of 


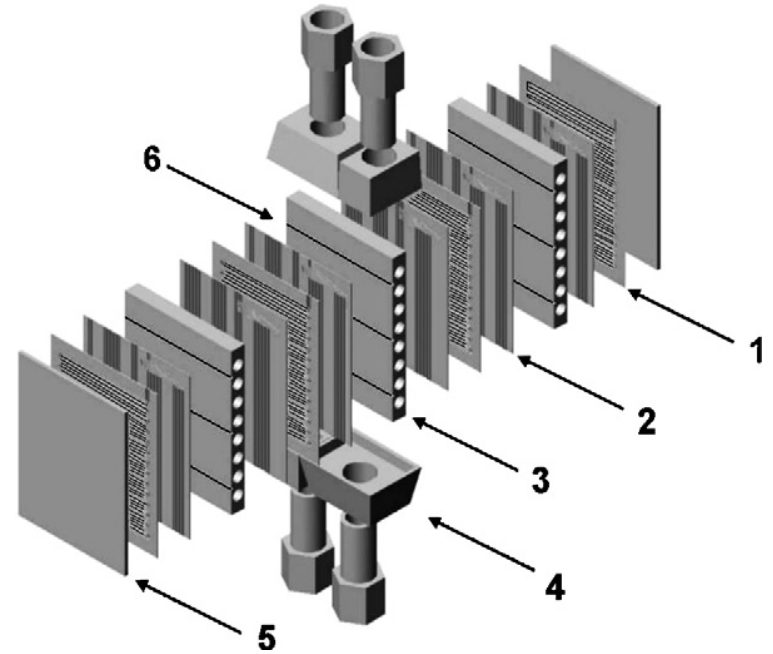

Fig. 1. Schematic drawing of a microstructured reactor FTC-I: (1) microstructured foil with three reaction channels; (2) microstructured foil with cooling channels; (3) plate with heating cartridge holes; (4) adapter; (5) cover plate; (6) channel for thermocouples. Once welded, the reactor size is $44 \mathrm{~mm} \times 33 \mathrm{~mm} \times 17 \mathrm{~mm}$ (without adapters) and it weights $199 \mathrm{~g}$.

stainless steel. The microstructured reactor is continuously electrically heated and periodically cooled with a flow of deionised water passing through the cooling foils.

The reaction and cooling foils have channels prepared by wet chemical etching as presented in Fig. 2. Three parallel channels are designed on each reaction foil to increase the residence time of the gas within the reactor and to have a high surface area. The length of each reaction channel is $764 \mathrm{~mm}$, the width $320 \mu \mathrm{m}$ and the depth $130 \mu \mathrm{m}$. The total reaction volume of the 12 channels within the reactor containing four reaction foils is approximately $300 \mu 1$.

Once the reactor is assembled, the microchannels on the reaction foils are coated by alumina using the conventional sol-gel technique [6]. For this purpose the channels are flushed out by a sol-gel solution, dried at $340 \mathrm{~K}$ overnight, heated to $770 \mathrm{~K}$ with a ramp of $3 \mathrm{~K} \mathrm{~min}^{-1}$ and calcined at $770 \mathrm{~K}$ for $5 \mathrm{~h}$. Platinum is deposed on the alumina layer by wet impregnation using a solution of $\mathrm{Pt}\left(\mathrm{NO}_{3}\right)_{2}(0.5 \mathrm{~mol} / \mathrm{l})$ followed by drying and calcinations under the same conditions as for the alumina coating.

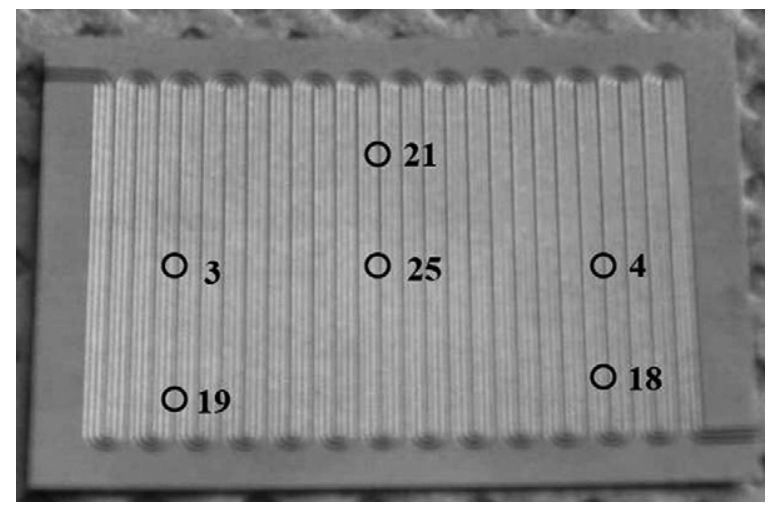

Fig. 2. Photo of a microstructured foil with reaction channels in form of parallel passes: $44 \mathrm{~mm} \times 33 \mathrm{~mm} \times 0.2 \mathrm{~mm}$. Each black circle with a number represents a position where a thermocouple was placed.

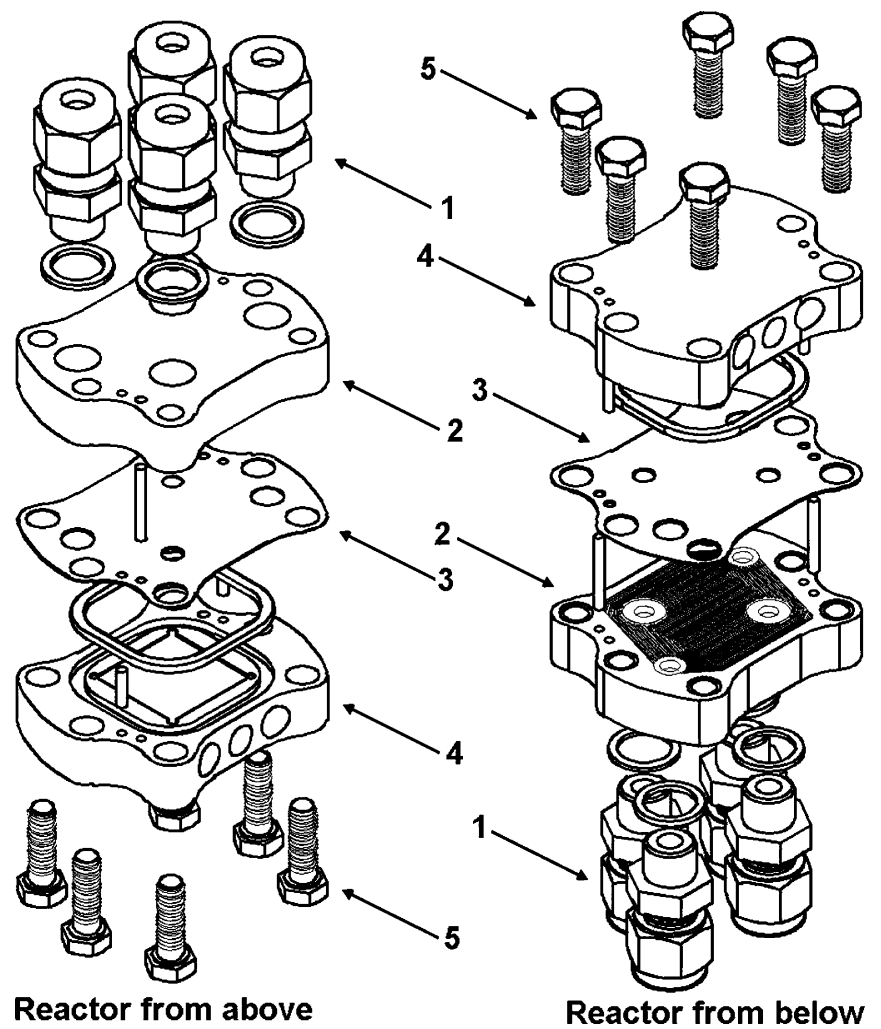

Fig. 3. Schematic drawing of the FTC-II reactor: (1) adapters; (2) top plate with microchannels for cooling flow; (3) blind foil for closing the cooling microchannels; (4) base plate with reaction chamber and holes for heating cartridges; (5) tightening screws.

The second reactor (FTC-II) consists of two stainless steel plates fixed together with six bolts (see Fig. 3). The bottom plate has a small square chamber $(20 \mathrm{~mm} \times 20 \mathrm{~mm} \times 1 \mathrm{~mm})$ and three holes for the heating cartridges. The chamber can accommodate different plates with catalytic material. The top plate has microchannels for the cooling water flow. The cooling channels are isolated from the reaction chamber by a blind welded foil. Four standard screw fittings (Swagelok $6 \mathrm{~mm}$ ) are welded on the top plate to connect the reactor with the gas and cooling water feed lines.

Once sealed, the size of the reactor is $53 \mathrm{~mm} \times$ $35 \mathrm{~mm} \times 20 \mathrm{~mm}$ (without adapters) and it weights $305 \mathrm{~g}$. The reactor is continuously heated by electric cartridges and periodically cooled by water flowing through the cooling channels.

The temperature in the reactor is measured by two thermocouples introduced in the gas fittings having their ends pressed into the metallic sintered metal fibers plate. A more detailed description of the experimental is available in $[4,5]$. The gas used for all the experimental measurements is a mixture of 5\% $\mathrm{CO}$ and $26 \% \mathrm{O}_{2}$ in $\mathrm{N}_{2}$. The flow is $300 \mathrm{ml} \mathrm{min}^{-1}$ (STP) giving a pressure of 2 bar at the reactor inlet with the outlet under ambient pressure.

Fourier transform infrared spectroscopy (FTIR) is used to measure online $\mathrm{CO}$ and $\mathrm{CO}_{2}$ concentration at the reactor outlet. Oxygen is infrared inactive and cannot be quantified using this method. 


\subsection{Catalyst preparation}

The catalyst used for $\mathrm{CO}$ oxidation in the reactor FTC-II was prepared on the base of a small plate $(20 \mathrm{~mm} \times 20 \mathrm{~mm} \times$ $0.4 \mathrm{~mm}$ ) of sintered metal fibers (SMF) filter [7,8]. The SMF filter supplied by the Southwest Screens \& Filters SA, Belgium, was made of stainless steel ( $\mathrm{Cr}$ 16-18; Ni 10-13; Mo 2-2.5; $\mathrm{C}<0.01$; Fe balance) in the form of a uniform pore panel $(80 \%$ porosity, $675 \mathrm{~g} / \mathrm{m}^{2}$ ). The plate was first calcined at $1170 \mathrm{~K}$ for $8 \mathrm{~h}$ and then coated with an alumina layer using an aqueous solution containing $3 \mathrm{wt}$. $\% \mathrm{Al}_{2} \mathrm{O}_{3}$ [9]. The coating operation is repeated three times to ensure a homogeneous $5 \mathrm{wt} \%$ coverage of the metal fibers by $\mathrm{Al}_{2} \mathrm{O}_{3}$. The specific BET surface area, as determined by Sorptomatic 1990 , was $13.7 \mathrm{~m}^{2} / \mathrm{g}$ for the final $\mathrm{Al}_{2} \mathrm{O}_{3} / \mathrm{SMF}$ support. This corresponds to $\sim 250 \mathrm{~m}^{2} / \mathrm{g}$ of alumina coating. Platinum was deposited by impregnation of the $\mathrm{Al}_{2} \mathrm{O}_{3}$ (5\%)/SMF support with an aqueous $\mathrm{H}_{2} \mathrm{PtCl}_{6}(1.25 \mathrm{wt}$ \%) solution followed by drying at room temperature and calcination at $770 \mathrm{~K}$ for $3 \mathrm{~h}$ in air. This catalytic plate is placed in the reaction chamber and then the reactor is sealed. The reduction of the platinum is performed before the reaction by heating the reactor from room temperature to $770 \mathrm{~K}$ at $10 \mathrm{~K} \mathrm{~min}^{-1}$ under a flow of $\operatorname{Ar}\left(11 \mathrm{~min}^{-1}\right)$ through the channels, keeping the temperature at $770 \mathrm{~K}$ for $2 \mathrm{~h}$ under $0.51 \mathrm{~min}^{-1} \mathrm{H}_{2}(0.5$ vol. $\%)$ in Ar and cooling under Ar flow $\left(11 \mathrm{~min}^{-1}\right)$.

\section{Experimental results and discussions}

\subsection{Thermal characterization of the FTC-I reactor}

The FTC-I microstructured reactor under stationary temperature conditions demonstrated a homogeneous temperature profile [10]. The different zones of the reactor showed the same temperature. However, when the temperature rapidly changes in a periodic manner, the situation observed was totally different. This can be seen in Fig. 4. The reactor allows very fast heating, but has a rather big mass, which prevents thermal homogeneity under non-stationary conditions.

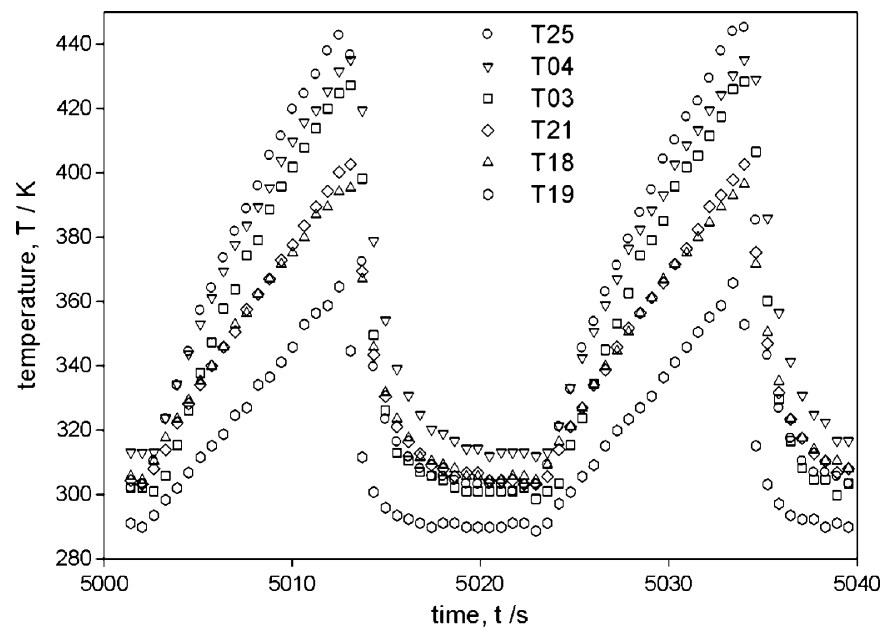

Fig. 4. Temperature variations during temperature cycling within the FTC-I reactor at different positions represented in Fig. 2. The mean amplitude is $120 \mathrm{~K}$ and the frequency $0.05 \mathrm{~Hz}$.
The maximal temperature difference between two positions in the microstructured reactor is seen to be $80 \mathrm{~K}$. The thermocouple T19, which is located near the cooling water inlet, shows a lower temperature as compared to the other reactor zones, and the amplitude observed was smaller. This zone of the reactor is cooled more effectively than the zone near the cooling water outlet. This can be explained by partial water evaporation. The amplitude of the temperature variation near the cooling water outlet (T4) is attenuated due to the lower heat capacity of water vapour as compared to liquid water, thus diminishing the cooling efficiency at the end of the cooling channels. The temperature at the edge of the reactor is lower than in the middle due to the thermal losses by radiation (T21) and conduction through the fittings and gas connections (T18).

\subsection{Thermal characterization of the FTC-II reactor}

The temperature profile measured under non-stationary temperature conditions for the microstructured reactor FTC-II is more homogeneous compared to the one obtained for the FTC-I. Fig. 5 presents temperature variations during a fast temperature cycling experiment at the inlet and at the outlet of the microstructured reactor. The maximum temperature difference between the reactor inlet and outlet was found to be only $15 \mathrm{~K}$.

Due to the very short distance between the two measurement points $(<20 \mathrm{~mm})$ and good heat conductivity of the sintered metal fibers [11], a hot spot in the middle of the reactor is not possible. The improved thermal homogeneity of the FTC-II reactor under non-stationary temperature conditions makes this device suitable for studying the influence of fast temperature oscillations on heterogeneously catalyzed reactions.

\subsection{Catalytic $\mathrm{CO}$ oxidation}

The CO oxidation is a suitable model reaction to study the effect of thermal unsteady state on the product yield. This reaction has been previously studied and a mechanism has been

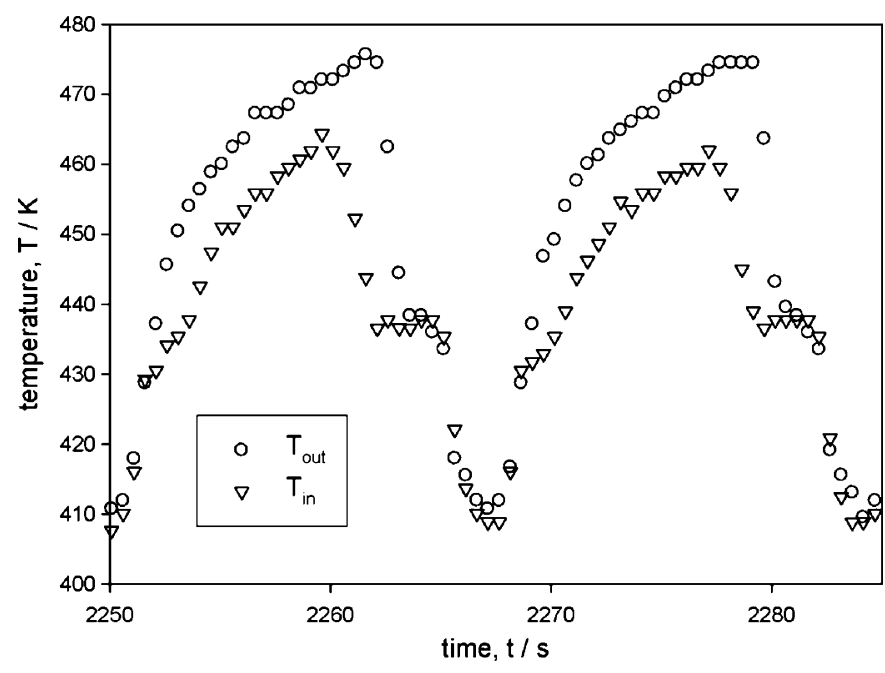

Fig. 5. Variation of the microstructured reactor temperature during temperature cycling. The mean amplitude is $60 \mathrm{~K}$ and the frequency $0.06 \mathrm{~Hz}$. 

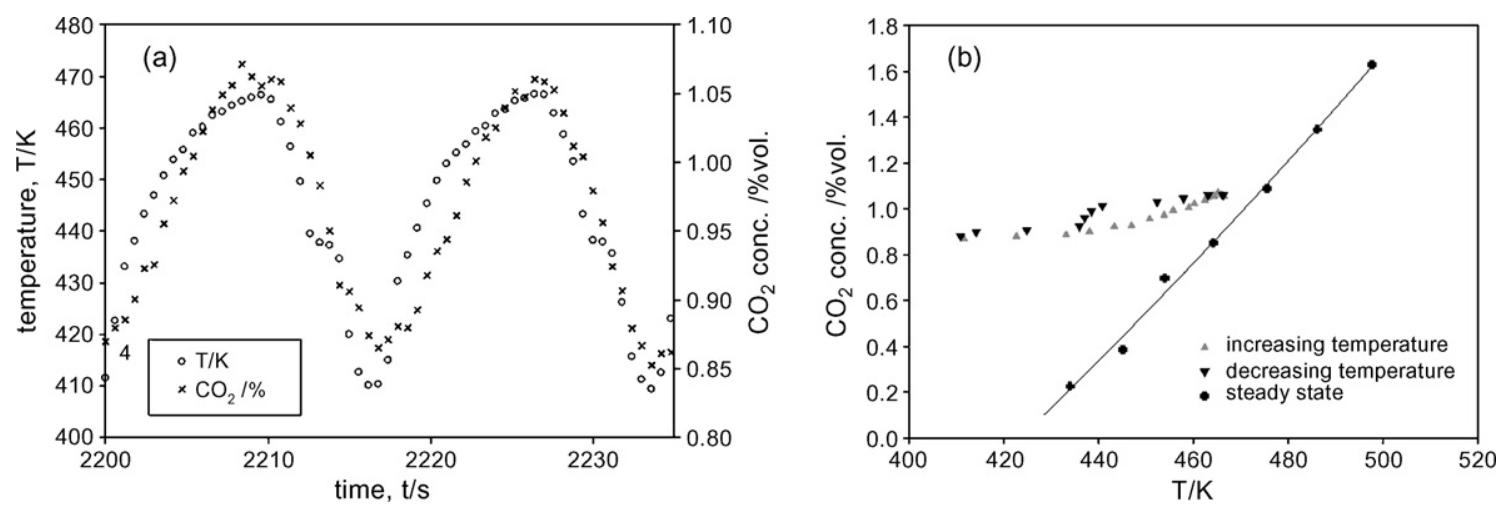

Fig. 6. $\mathrm{CO}_{2}$ concentration at the reactor exit and mean temperature under non-steady-state operation (a). $\mathrm{CO}_{2}$ concentration as function of temperature under thermal stationary and non-stationary conditions (b). Temperature amplitude: $60 \mathrm{~K}$, length of period: $17 \mathrm{~s}$.

proposed, see for example [12-14]. Cutlip [15] mentioned in his study that changes in the surface coverage during periodic concentration cycling of the reactants lead to a higher productivity. If such changes in surface coverage can be obtained by forced periodic temperature changes, a similar increase of the reaction rate and product yield can be expected. According to Nibbelke et al. [12], CO oxidation is inhibited by the preferential adsorption of $\mathrm{CO}$ on the catalyst surface compared to the adsorption of oxygen. As predicted theoretically and proven experimentally [16,17], periodic operation leads to a significant increase of the mean reaction rate for reactions with strong educt inhibition. This is a further indication that periodic temperature oscillation can positively affect the reaction performance.

A comparison of the $\mathrm{CO}_{2}$ concentration obtained under steady-state conditions and under thermal oscillations is presented in Fig. 6.

In Fig. 6a the instantaneous mean temperature and $\mathrm{CO}_{2}$ concentrations are plotted for two periods with a length of $17 \mathrm{~s}$ corresponding to a frequency of $0.06 \mathrm{~Hz}$. The concentration of $\mathrm{CO}_{2}$ follows the imposed temperature fluctuations with a slight phase shift. In Fig. $6 \mathrm{~b}$ the measured concentrations are plotted as function of the instantaneous temperature within one period. Due to the phase shift between temperature and concentration oscillations, the $\mathrm{CO}_{2}$ concentration for increasing temperatures is always smaller compared to those measured for decreasing temperatures. As can be seen in Fig. 6b, the $\mathrm{CO}_{2}$ concentrations measured at the exit of the reactor at any temperature are higher under thermal instationary conditions when compared to the values obtained under steadystate.

The effect observed is probably due to variations of the surface coverage by the reactive species obtained during the temperature changes. This change in coverage is beneficial for the reaction rate, as observed in the case of concentration oscillations [16]. These quantitative results confirm the qualitative ones obtained by Brandner $[4,5]$ and are similar to the ones presented by Hansen et al. [18] using a silicon microreactor.

The results obtained are encouraging and further experimental measurements are planned varying the frequency and temperature amplitude applied to the reactor. This may allow a better understanding of the observed phenomenon.

\section{Conclusions}

- A microstructured stainless steel reactor has been developed and shown to be suitable for studying the influence of fast periodic temperature changes on heterogeneously catalyzed reactions. Temperature oscillations up to $60 \mathrm{~K}$ at a frequency of $0.06 \mathrm{~Hz}$ are demonstrated experimentally with gradients of at most $15 \mathrm{~K}$ within the reactor.

- The results obtained for the catalytic $\mathrm{CO}$ oxidation under thermal unsteady-state show an increase in the instantaneous CO conversion compared to the thermal steady-state.

\section{References}

[1] P. Silveston, R.R. Hudgins, A. Renken, Periodic operation of catalytic reactors-introduction and overview, Catal. Today 25 (1995) 91-112.

[2] K.W. Hansen, S.B. Joergensen, Experimental investigation of the dynamics of a catalytic fixed bed reactor, Adv. Chem. Ser. 133 (1974) 505-517.

[3] R.C. Lin, Periodic processes in chemical engineering, Ph.D. Thesis, Rice University, 1966.

[4] J.J. Brandner, Entwicklung von Mikrostrukturreaktoren zum thermisch instationären Betrieb chemischer Reaktionen, Ph.D. Thesis, IMVT, Forschungszentrum Karlsruhe, 2003, Report number FZKA 6891.

[5] J.J. Brandner, G. Emig, M.A. Liauw, K. Schubert, Fast temperature cycling in microstructure devices, Chem. Eng. J. 101 (2004) 217-224.

[6] R. Wunsch, M. Fichtner, O. Görke, H.-S. Katja, K. Schubert, Process of applying $\mathrm{Al}_{2} \mathrm{O}_{3}$ coatings in microchannels of completely manufactured reactors, Chem. Eng. Technol. 25 (2002) 700-703.

[7] I. Yuranov, L. Kiwi-Minsker, A. Renken, Structured combustion catalysts based on sintered metal fibre filters, Appl. Catal. B: Environ. 43 (2003) 217-227.

[8] K. Nikolajsen, L. Kiwi-Minsker, A. Renken, Structured fixed-bed adsorber based on zeolite/sintered metal fiber for low concentration VOC removal, Chem. Eng. Res. Des. 84 (A7) (2006) 562-568.

[9] Y. Kobayashi, T. Ishizak, Y. Kurokawa, Preparation of alumina films by the sol-gel method, J. Mater. Sci. 40 (2005) 263-283.

[10] P. Léger, Thermal and pressure drop characterization of a microstructured reactor for fast temperature cycling, Diploma Work, IMVT, Forschungszentrum Karlsruhe, 2005.

[11] D.R. Cahela, B.J. Tatarchuk, Permeability of sintered microfibrous composites for heterogeneous catalysis and other chemical opportunities, Catal. Today 69 (2001) 33-39.

[12] R.H. Nibbelke, M.A.J. Campman, J.H.B.J. Hoebink, G.B. Marin, Kinetic study of the $\mathrm{CO}$ oxidation over Pt/g- $\mathrm{Al}_{2} \mathrm{O}_{3}$ and $\mathrm{Pt} / \mathrm{Rh} / \mathrm{CeO}_{2} / \mathrm{g}-\mathrm{Al}_{2} \mathrm{O}_{3}$ in the presence of $\mathrm{H}_{2} \mathrm{O}$ and $\mathrm{CO}_{2}$, J. Catal. 171 (1997) 358-373.

[13] T. Engel, G. Ertl, A molecular beam investigation of the catalytic oxidation of CO on Pd(1 11 ), J. Chem. Phys. 69 (1978) 1267-1281. 
[14] M. Rinnemo, D. Kulginov, S. Johansson, K.L. Wong, V.P. Zhdanov, B. Kasemo, Catalytic ignition in the $\mathrm{CO}-\mathrm{O}_{2}$ reaction on platinum: experiment and simulations, Surf. Sci. 376 (1997) 297-309.

[15] M.B. Cutlip, Concentration forcing of catalytic surface rate processes, AIChE J. 25 (1979) 502-508.

[16] M.A. Truffer, A. Renken, Transient behaviour of heterogeneous catalytic reactions with educt inhibition, AIChE J. 32 (10) (1986) 1612-1621.
[17] E. Gulari, X. Zhou, C. Sze, Catalytic oxidation of carbon monoxide under periodic and transient operation, Catal. Today 25 (1995) 145157.

[18] H.A. Hansen, J.L. Olsen, S. Jensen, O. Hansen, U.J. Quaade, Rate enhancement in microfabricated chemicals reactors under fast forced temperature oscillations, Catal. Commun. 7 (2006) 272-276. 